\title{
FRUIT-FLIES OF ECONOMIC IMPORTANCE IN CALIFORNIA
}

By Henry H. P. Severin, Berkeley, Cal.

(Withdrawn for publication elsewhere)

The paper was discussed by H. E. Burke, A. W. Morrill, R. W. Doane and others.

Chatrman A. W. Morrill: The next paper, by Prof. A. L. Lovett, will be read by the secretary.

\section{NICOTINE SULPHATE AS A POISON FOR INSECTS}

\section{A. L. Lovetr, Entomologist, Oregon Agricultural Experiment Station}

A suggestion of nicotine sulphate as a stomach poison for insects was first brought to the writer's attention after reading the report of Mr. F. E. DeSellem, inspector at large, of North Yakima, Washington, on Black Leaf 40 as a spray for the codling moth.

Since the completion of the work included in this paper, has appeared the excellent article on "Nicotine as an Insecticide" by Mr. McIndoo, in the Journal of Agricultural Research, and still more recently the 1916 Horticultural Report of Yakima County, Washington, with the two seasons' rather startling results of Mr. DeSellem on the control of the codling moth. The results included in this paper supplement both in a measure and are offered as additional data on a very interesting topic. Nicotine sulphate as a contact insecticide is considered a very efficient, but expensive spray. The possibility of its broader insecticidal properties in commercial spraying as indicated in these papers may alter our present conception as to value versus service.

\section{Series 1. For Foliage Eating Caterpillars}

The caterpillars used in the tests were our common tent caterpillars (Malacosoma pluvialis Stretch). They were collected, tent and all, in the field feeding on the foliage of the wild rose. With the exception of Experiment A the foliage was allowed to dry for hours after applying the spray before introducing the caterpillars.

ExPERIMENT A.

April 9, 1916. 9.00 a. m.

Sprayed foliage of wild rose with "Pratt's Nicotine 40" 1-400, thoroughly saturating the foliage with a fine misty spray. Placed approximately 600 newly hatched larvæ of the tent caterpillar $(M$. 
pluvialis) on the wet foliage. The caterpillars exhibited a most decided aversion to the sprayed foliage, crawling about, collecting in masses and suspending themselves on elongated web ropes and dropping off. By noon, fully 60 per cent were apparently dead, though none had fed. These died in a balled up heap in the center of the mass of foliage. The few remaining caterpillars were restless, sick and writhing about. Observations at $5.00 \mathrm{p}$. m. showed about all dead; some which had dropped apparently dead, showed signs of life, but were very sick. The next morning, A pril 10, all were dead or had left. A fair per cent of those which dropped had recovered and crawled away. One small incision in the margin of a leaf was observed, but there were no other apparent signs of feeding.

EXPERIMENT B.

April 13, 1916. 8.45 p. m.

Sprayed foliage of apple as follows:

No. 1, Pratt's Nicotine $401-800$

No. 2, Black Leaf 40 1-1200

Applied as fine misty spray thoroughly saturating foliage. Placed on table to dry. April 14, 9.00 a. m., placed approximately 300 small caterpillars on each No. 1 and No. 2. Foliage perfectly dry.

The caterpillars showed a decided aversion, were restless, crawled about, formed long web ropes and dropped off. . Often one would be observed to rear the head and half of the body from the foliage, writhe about and spew up drops of dark liquid as grasshoppers do, apparently very sick. At 3.00 p. m., 50 per cent were apparently dead, the others very sick. Many which had dropped and lay curled in grotesque positions as though having died in great pain, eventually recovered (after 3 hours or more) and crawled away. The following day, April 15, a few were observed to have fed on both Nos. 1 and 2. Where they had fed, they were apparently in all cases really dead. One fact stood out particularly, of the many which had dropped, apparently dead, without having fed, they had almost without exception, recovered and crawled away. The drop on No. 2 was a little heavier than on No. 1, with a little more feeding indicated on No. 1. The caterpillars were about all dead or had crawled away the next day, April 16, from both Nos. 1 and 2. To see if the action of the material was still effective, 75 fresh caterpillars were placed on No. 2. The action of the caterpillars was the same as that of earlier forms, restless, sick and dropping off. This would indicate that the action, whatever it is, extends over a period of three days at least. 


\section{Experiment C.}

May 5, 1916.

Sprayed apple foliage with following:

No. 3, Black Leaf 40, 1-800

No. 4, Black Leaf 40, 1-1200

Thoroughly covered foliage with fine misty spray and allowed to dry for six hours. Placed approximately 1,000 half-mature tent caterpillars on each.

The results were practically identical with those of Experiments A and $B$ with the immature forms. The material was apparently very repulsive, though no odor of nicotine could be detected. The foliage was placed where a breeze could blow across it. The caterpillars continued to act restless, dropped, writhed and spewed. The effect of the spray on these larger forms was slower. Also, more caterpillars were used in the tests. Daily observations were made up until May 19, a total of 14 days, when approximately all had left the sprayed foliage. Each day a number would drop, lie for approximately three hours as though dead, then recover and crawl away. Those which crawled away collected in a mass on the sill of the window. On May 10 and 11 these forms were collected and placed on fresh unsprayed foliage. Here they fed with great gusto and apparently showed no ill effects of the recent illness. On May 11, two caterpillars were found dead on No. 3; the foliage showed small feeding punctures. There were three dead on No. 4, which also showed slight evidence of feeding. The foliage was changed on May 12, first allowing it to dry thoroughly after applying the spray. On May 19, seven caterpillars were dead under No. 3 and 12 under No. 4. Feeding for the entire period amounted to a total of about two fair-sized leaves.

EXPERIMENT D.

May 19.

Dipped camel's hair brushes in Nicotine Sulphate 40 per cent and treated nearly mature caterpillars as follows:

No. 1. Bladk Leaf $40,1-800$, painted ventral surfaces of 10 caterpillars with moist brush and then placed caterpillars on fresh unsprayed apple foliage.

No. 2. Pratt's Nicotine 40, 1-800, allowed brush to dry for 24 hours, painted ventral surface of 10 caterpillars and placed on fresh unsprayed apple foliage.

No. 3. Black Leaf $40,1-1200$, allowed to dry 24 hours and treated as above.

No. 4. Pratt's Nicotine 40, 1-1200 treated as No. 1.

No. 1 and No. 4 nauseated, spewed up and dropped off; eventually recovered.

No. 2 and No. 3 restless for a time but eventually commenced feeding and were apparently normal. Not sick. 


\section{Conclusions}

Nicotine sulphate is a very powerful repellent for caterpillars. They will not ordinarily feed from choice on foliage sprayed with it. Where feeding does take place, the action of the nicotine is apparently rapid and sure, even small bits of foliage sprayed with comparatively weak solutions, where devoured, killing after a short time. To what property of the spray one may attribute the general sick condition of the caterpillars is discussed in Mr. McIndoo's paper, page 98. Paralysis of the nerves by the volatile nicotine passing in through the trachex as he suggests is the most feasible explanation. The volatilization of nicotine sulphate must be very slow as this material is, theoretically, non-volatile. The possibility of the active agent being absorbed by the feet or through the skin and thus carried to the nerve centers is also suggested.

\section{Series B, For Codling Moth}

The tests of nicotine sulphate for the control of the codling moth were very unsatisfactsry and can hardly be considered good experimental data. The immediate cause for failure was an unavoidable late change in plans. The factors which make the test of little value are as follows: The orchard tract available for the test consisted of a rundown orchard of mixed varieties with their necessary individual variations. No comparison was made against the standard lead arsenate application. The nicotine sulphate was used in combination with lime-sulphur instead of soap. The season was a very backward one and the generations of the codling moth were very much delayed. A summary of the test is included in this paper that one may judge the results for whatever value they may have.

Four applications were made: 1 , The calyx spray, May 10;2, When eggs of first generation were deposited, June $16 ; 3$, When first adults of second generation appeared, August 2; and 4, When majority of second generation moths were depositing eggs, September 8 .

The following materials were used at each application:

1. Niagara dust sulphur 85 per cent plus Corona lead arsenate 15 . per cent, as a dust.

2. Black Leaf $40,1-400$ plus lime sulphur $32^{\circ}$ B., 1-35.

3. Pratt's Nicotine $40,1-800$ plus lime sulphur $32^{\circ}, 1-35$.

4. Black Leaf $40,1-1200$ plus lime sulphur $32^{\circ}, 1-35$.

While none of the materials gave satisfactory control, the comparative resuits are interesting. In the check, there were 29.65 per cent of wormy apples. Nicotine sulphate 1-1200 and 1-800 show but slight control, having respectively 26.8 and 26 per cent of wormy apples. 
(Cydia pomonella)

(Total count 20,396 apples)

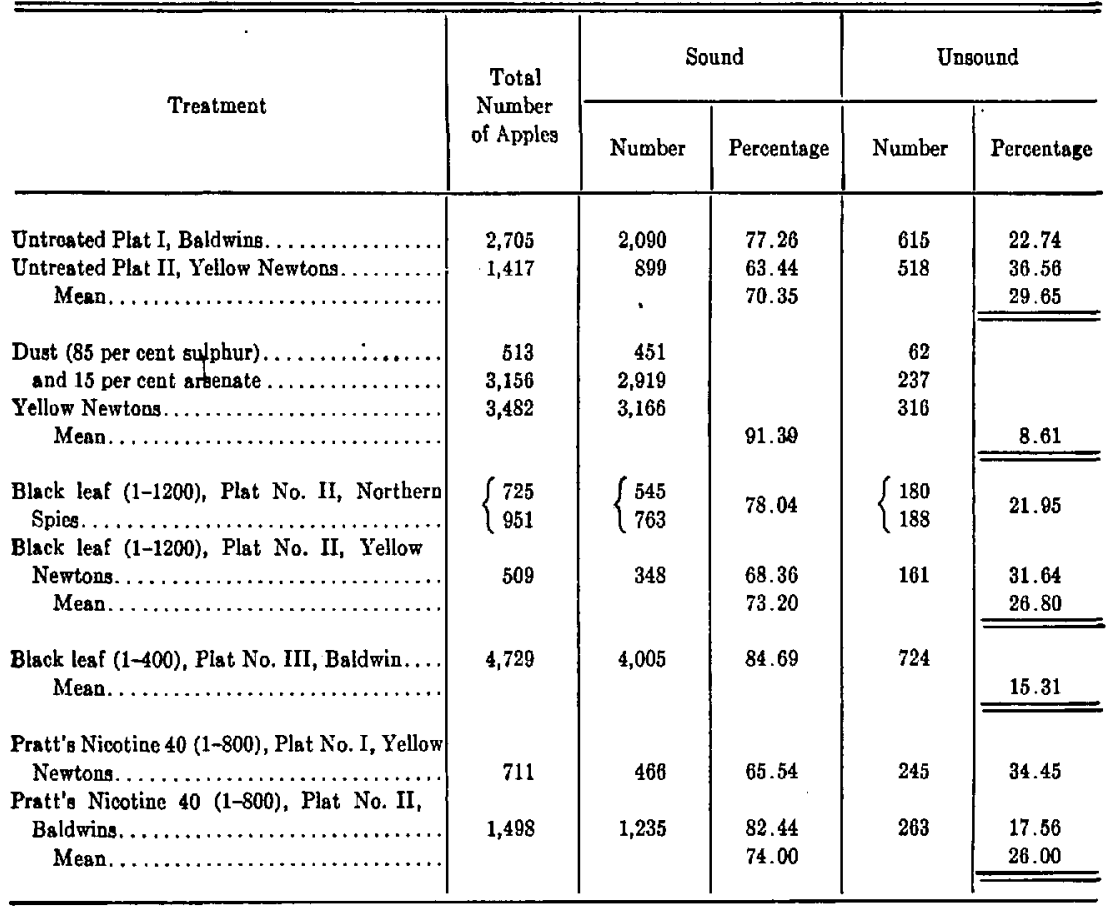

Nicotine sulphate $1-400$ gave approximately one-half control or 15.31 per cent worms. The dust application gave by far the best control, showing only 8.6 per cent worms. The foliage of the dusted trees showed to an advantage. This material also checked the scab to a very fair degree, though the work was started too late to afford satisfactory control here.

1916. McIndoo, N. E. Effects of Nicotine as an Insecticide. Jour. Agri. Research, VII, pp. 89-121. 1916.

1916. DeSellem, F. E. Nicotine Sulphate for the Control of the Codling Moth. Yakima County Hort. Rept. 1916, pp. 62-72.

Chairman A. W. Morrill: The next paper by Prof. C. P. Gillette and $L$. C. Bragg will be read by the secretary. 